\title{
What Difference Can "Experience" Make to Pragmatism?
}

\section{Gregory Pappas}

\section{(2) OpenEdition}

\section{Journals}

\section{Electronic version}

URL: http://journals.openedition.org/ejpap/322

DOI: 10.4000/ejpap.322

ISSN: 2036-4091

\section{Publisher}

Associazione Pragma

\section{Electronic reference}

Gregory Pappas, « What Difference Can "Experience" Make to Pragmatism? », European Journal of Pragmatism and American Philosophy [Online], VI-2 | 2014, Online since 24 December 2014, connection on 30 April 2019. URL : http://journals.openedition.org/ejpap/322 ; DOI : 10.4000/ejpap.322

\section{(c) $(1)(9)$}

Author retains copyright and grants the European Journal of Pragmatism and American Philosophy right of first publication with the work simultaneously licensed under a Creative Commons AttributionNonCommercial-NoDerivatives 4.0 International License. 


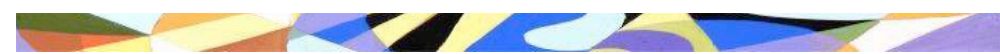

Gregory Pappas*

What Difference Can “Experience” Make to Pragmatism?

Abstract: The centrality of "experience" for Pragmatism has been challenged. Neopragmatists insinuate that experienced-centered pragmatists (ECP) are conservative in hanging on to a passé philosophical notion. This paper argues that, on the contrary, ECP continue to insist on experience because of its present relevance and its future potential for philosophy, but this requires understanding what the classical figures were trying to accomplish with the notion of experience. In the first section I remind readers what these functions are; the rest of the paper argues that experience continues to serve Pragmatism well, in particular in their view of inquiry. The notion of experience was what enabled Dewey to put forth a view of inquiry as guided by the qualitative that is still robust, defensible, and relevant, and that is not susceptible to the objections and dangers found in language centered Pragmatism (LCP).

The main argument is an extension of a recent argument presented by Richard Bernstein in The Pragmatist Turn (2010). The second section of this essay presents Bernstein's argument and shows how it can be significantly extended or reinforced by showing the difference experience, in particular its qualitative character, makes to a pragmatist view of inquiry. The third section addresses what Dewey means by the qualitative. The fourth section presents the specific functions the qualitative has on thinking (inquiry). The qualitative accounts for the unity, continuity, coherence, direction, and self-regulation of inquiry. These are the important functions of what is noncognitive and nonlinguistic, precisely what LCP wishes to deny or not emphasize in giving up on experience. These functions are presently being corroborated by research in the science of cognition. The essay concludes in the fifth section with some implications of the arguments presented in the contemporary debate between LCP and ECP. If, as I argue, what is at stake in Pragmatism giving up experience is what gives its notion of inquiry its robust and promising character, then ECP is cutting-edge Pragmatism and LCP is more like "Paleopragmatism".

The centrality of "experience" for Pragmatism has been challenged. Neopragmatists, starting with Richard Rorty and more recently Robert Brandom, have argued that Pragmatism could do well if it eliminated experience altogether. Brandom says, "Rorty and I both think that...the notion of experience is simply outmoded [...]. I agree with him that there is no useful way to rehabilitate the concept of experience. We just need to do without that"1. Instead, they insist that we need to move toward a languagecentered Pragmatism (LCP hereafter) ${ }^{2}$. LCP insinuate that experienced-centered

\footnotetext{
* Texas A\&M University [g-pappas@tamu.edu]

1. Brandom (2002: 5).

2. Rorty's call to eliminate experience in Pragmatism has led to the development of a more languagecentered pragmatism, sometimes called "neopragmatism". This language-centered strategy has become important in the work of figures such as Robert Brandom, Huw Price, Cheryl Misak, Michael Williams, and Bjørn Ramberg.
} 
pragmatists $(\mathrm{ECP})^{3}$ are conservative in hanging on to a passé philosophical notion. This paper argues that, on the contrary, ECP continue to insist on experience because of its present relevance and functionality as well as its future potential for philosophy, but this requires understanding what the classical figures were trying to accomplish with the notion of experience. In the first section I remind readers what these functions are; the rest of the paper argues that experience continues to serve Pragmatism well, in particular in their view of inquiry.

I argue that the notion of experience was what enabled the Classical American pragmatists to put forth a view of inquiry that is still robust, defensible, and relevant, and that is not susceptible to the objections and dangers found in language centered Pragmatism (LCP). In The Pragmatic Turn (2010) Bernstein makes this same general argument, however, his defense of the importance of experience to the pragmatic conception of inquiry is limited to showing the difference that "secondness" (an aspect of experience presented by Charles S. Peirce) makes. Starting in the second section of this essay, I significantly extend or reinforce Bernstein's argument by showing the difference that the qualitative aspect of experience makes to a pragmatists view of inquiry. This requires revisiting and reconstructing (in the third and fourth sections), John Dewey's view of the nature and functions of the qualitative in all inquiries. For among the classical pragmatists he was the one that developed further the idea that all thinking is qualitative.

For Dewey the qualitative accounts for how inquirers determine continuity, relevance, coherence, and reach judgments in inquiry. These are the important functions of what is noncognitive and nonlinguistic, precisely what LCP wishes to deny or not emphasize in giving up on experience. These views of Dewey are among the most significant consequences or fruits of his metaphilosophical commitment to experience. Moreover, they are presently being corroborated by research in the science of cognition. The essay concludes in the fifth section with some implications of the arguments presented to the contemporary debate between LCP and ECP. I argue that what is at stake in Pragmatism giving up experience is what gives its notion of inquiry its robust and promising character, therefore ECP is cutting-edge Pragmatism and LCP is more like "Paleopragmatism".

\section{The Function of Experience in Pragmatism}

The challenge presented by LCP to ECP has the merit of forcing all pragmatists not take for granted the philosophical legacy of the classical figures. However, the problem with the challenges that have been brought so far by LCP is they are remarkably weak, they have mostly miss their target, i.e. they have little to do with what classical pragmatist meant by "experience". I will not review them here since

3. In this paper ECP is understood as all those contemporary philosophers that have continued to adop and reconstruct the notion of experience, especially as it appears in the works of William James and John Dewey. This experience-centered approach informs the work of a variety of recent contemporary pragmatists such as Thomas Alexander, Richard Shusterman, Charlene Haddock Seigfried, Gregory Pappas, Douglas Anderson, and many others. 
enough has already been published on this issue ${ }^{4}$. Proper reevaluation of experience for Pragmatism needs to start by considering what the classical figures were trying to accomplish with the notion.

The notion of experience served three broadly related functions in pragmatist philosophy: (1) the critical function of undermining the starting point shared by modern philosophy; (2) the preventative function of keeping pragmatists from inadvertently making some common mistakes in philosophy, such as "the philosophical fallacy" in all of its versions and manifestations including starting with dualisms, reductionism, neglect of context, and intellectualism (equating the real with what is known); and (3) the more edifying and reconstructive function of entailing some positive methodological prescriptions that resulted in a reconstruction of traditional notions of inquiry, self, morality, art, religion, and so on.

Of all the classical pragmatists Dewey is the most explicit about these metaphilosophical functions of experience. It is unfortunate that in spite of his clarity about what experience means for Pragmatism LCP critics continue to confuse it with the epistemological notion of experience as a cognitive state or as sense perception. Dewey states, "Experience for philosophy is method, not distinctive subject-matter. And it also reveals the sort of method that philosophy needs" (LW 1:371) ${ }^{6}$. Dewey is open to dropping the term "experience" or try something else if it is no longer needed and does not accomplish the above three functions. He says that if experience as method was "universally followed by philosophers, then the word and the notion of experience might be discarded" (LW 1: 372).

Throughout his philosophical career Dewey tried different ways to present what experience as method means. This is not the place to go into all the details about what experience as method entails for philosophy ${ }^{7}$; however, something must be said about why Dewey considered experience so important in light of the history of philosophy. This will give us a sense of how the three above functions are interrelated.

Pragmatism is a revolutionary philosophy in the history of philosophy because it criticizes the modern starting point and instead takes lived experience as the proper starting point of any philosophical investigation. According to the classical figures, underneath the debates among opposing schools in modern philosophy lies a common starting point that resulted in a certain view of experience, which in turn led to artificial and irresolvable problems. The history of Pragmatism can be understood as the history of the criticism of a starting point that has been and continues to be favored in philosophy. With each new articulation of what this favored starting point comes to, there is the hope of sophistication in the detection and prevention of this ill in philosophy. Peirce called it "Cartesianism" because he saw it in Descartes";

4. See Hildebrand 2003, Ralston 2013, Bernstein 2010, Pappas and Hildebrand 2010, and Levine 2012 5. For an explanations of all the different formulations of this fallacy see Pappas (2008: 17-42).

6. Citations of the works of John Dewey in this article refer to the critical editions published by Southern Illinois University Press. In the citations the initials of the series are followed by volume and page numbers. Abbreviations for the critical edition are: EW The Early Works (1982-1898), MW The Middle Works (1899-1924), LW The Latter Works (1925-1952).

7. See Alexander (2013: 1-54); Pappas (2008: 17-42).

8. In a Monist article published in 1905, Peirce made the following remarks: "Philosophers of very 
James detected it in traditional empiricism and therefore called for a more "radical" empiricism. But once you get to Dewey, the failure to come to terms with the proper starting point was considered so common in philosophy that he decided to call it "the philosophical fallacy" (LW 1: 51).

The problem is that philosophers tend to favor starting with a theoretical view of things, in particular one in which we are subjects or spectators of a world to be known. Pragmatism instead proposes the radical idea that philosophy should start where we are, i.e., in the midst of our concrete pretheoretical, practical, everyday experience, and continue to return to that for confirmation. This is what experience as method amounts to. This method would not be so important to Dewey if most philosophizing had been done from this empirical postulate and attitude. For the most part, however, the temptation of philosophers have been to start with theoretical abstractions and explanations about their everyday lives instead of making an effort to attend to the richness and particularity of our practical everyday contexts as they are lived.

If it was not for the fact that the word "practice" is commonly used to mean a certain narrow aspect of experience, practice, according to the classical pragmatist, is the adequate starting point because to be and start in experience is to be engaged in a practical, agentive way and not from a theoretical stance, as in the "Cartesian" contemplation of the objects of consciousness.

Experience as method accounts for the other themes associated with the classical pragmatists ${ }^{9}$. While important, the pragmatic maxim about the meaning of concepts is just one of many other consequences of taking lived experience as the starting point. It follows from their metaphilosophy that the meaning of concepts (including "truth") must be cashed out in experiential terms and consequences. There are, of course, important differences between James, Dewey, and Peirce in regard to their particular views about meaning, truth, and much more. Nevertheless, they share a metaphilosophy, one that continues to be valorize and applied by contemporary ECP.

I hope that this brief outline of the function of experience makes it clear what sort of argument LCP has to be able to produce in order to convince ECP to give up on experience. The burden of proof is on LCP to claim that some other notion, such as language, can better accomplish the above three functions or that the functions are no longer important. For ECP, experience continues to serve all of the above functions, notwithstanding the fact that the term is subject to misunderstandings. Experience allows Pragmatism to provide a full diagnosis of what has gone wrong with modern philosophy. Today it gives us a powerful basis for criticizing present debates, which

diverse stripes propose that philosophy shall start from one or another state of mind in which no man, least of all the beginner in philosophy, actually is. One proposes that you shall begin by doubting everything, and says that there is only one thing that you cannot doubt, as if doubting were 'as easy as lying'. Another proposes that we should begin by observing 'the first impressions of sense' [...]. But in truth, there is but one state of mind from which you can 'set out', namely, the very state of mind in which you actually find yourself at the time you do 'set out' - a state in which you are laden with an immense mass of cognition already formed, of which you cannot divest yourself if you would" (CP 5.416.).

9. Even their shared commitment to fallibilism and pluralism is a consequence of taking lived experience as their starting point. For one of the first things that strikes us about experience is that it is experienced as changing, open-ended, plural, and subject to possible improvement. 
are often family quarrels because of the same starting point. More importantly, it allows pragmatists today a way to criticize or improve the hypothesis or conclusions of the classical figures because they must be open to the possibility that some of the views of the classical figures may not fit experience as we find it today.

Of course, experience became more than a metaphilosophical commitment in that it resulted in a general view of experience, very different from the traditional notion, and one in which is experience is not reduced to a cognitive affair nor to a linguistic one, as LCP seem to entail - more on this later. This is a consequence of the edifying-reconstructive function previously mentioned (\#3 above). The particular ethics, metaphysics, epistemology, and aesthetics of the classical pragmatists were consequences of taking experience seriously so that in reply to the question of what difference experience makes to Pragmatism one can point to these fruits.

A comprehensive reexamination of experience for Pragmatism in light of the above three functions is beyond what can be properly accomplished in a single paper. Experience as a notion has to be reevaluated in light of its consequences in all areas of philosophy. In this paper I focus on one of these fruits, the particular areas of philosophy that have to do with the study of human thought and knowledge: epistemology and logic ${ }^{10}$.

The broad thesis to be defended is that, in regard to its conception of inquiry, Pragmatism is better off if it continues to work with the notion of experience rather than eliminate it and go along with neopragmatists' linguistic approach. By retaining experience we avoid certain problems endemic to an LCP approach and are able to continue to present an inclusive and rich conception of inquiry. The argument here is inspired by and can be seen as an extension of a recent argument by Richard Bernstein.

\section{Extending Bernstein's "Secondness" Argument}

In The Pragmatic Turn, Bernstein argues that a pragmatic conception of inquiry requires experience. Language-centered accounts of inquiry presented by neopragmatists make Pragmatism vulnerable to certain obvious objections and dead ends. Bernstein writes, "One of the great dangers of the so called 'linguistic turn' is the way it keeps sliding into linguistic idealism, where there is nothing that constrains our language"11. He points out that one can detect an "anxiety" in the recent work of McDowell and Habermas because "there is nothing that really constrains or ties down our network of beliefs"12. Bernstein argues that these difficulties could have been avoided had LCP adopted the classical figures' rich view of experience, but in particular what Charles S. Peirce called "secondness". This is the idea that

10. In spite of the narrow scope of my argument, it may well be the most effective in trying to convince philosophers of the importance of experience. Why? Because it shows the difference experience makes in epistemology. This is ironic since one of the main reasons that Dewey thought philosophers need experience was to do away with the unquestioned privilege of knowledge in modern philosophy. There is more to experience than knowledge. If I am right - that arguments about epistemology continue to be favored by philosophers - then this is further evidence that Pragmatism still needs experience.

11. Bernstein (2010: 134)

12. Bernstein (2010: 134) 
"experience involves bruteness, constraint, 'over-and-againstness'. Experience is our great teacher. And experience takes place by a series of surprises"13. Without this element, Bernstein argues, experimental inquiries lack friction.

Bernstein writes that "the insight that originally let philosophers to valorize experience - its brute compulsiveness - is what Peirce underscores with Secondness. Acknowledgement of this bruteness - the way in which experience 'says NO!' - is required to make sense of the self-corrective character of inquiry and experimentation" 14 . This is how Pragmatism can make sense of the self-corrective and experimental character of inquiry, and that there is more to rely on than our "conversational constraints" 15 . Secondness "does justice to what philosophers call their "realistic intuitions"" 16 . We do not need to reify a realm of facts that exists independently of any language, thought, or inquiry. Peirce does justice to the fallibility and openness of all inquiry "without losing touch with a reality that is independent of vagaries of me and you"17. Experience is what keeps Pragmatism from the danger of sliding into the language-communal relativism of Rorty. As Bernstein notes, "Peirce would have been repelled and horrified by Rorty's claim that the only constraints upon us are conversational constrains. To speak in this manner is to ignore the facticity, the surprise, shock, and brute constraint of our experiential encounters"18. "Redescription", Bernstein writes, "no matter how imaginative, is not enough"19. He concludes, "Contrary to the prevailing prejudice that the linguistic turn displaces oldfashioned talk about experience Peirce's conception of experience helps us to escape from some of the dead-ends of the linguistic turn" 20 .

Bernstein's argument is right on target, but he is too kind in his criticism. He misses an opportunity to develop an even stronger argument on behalf of experience. He limits his defense to the importance of secondness in having a robust and defensible view of inquiry. He leaves out what Peirce calls "firstness" and Dewey calls the "qualitative" as a central aspect of experience. It was Dewey among the pragmatists who was more explicit and elaborated why the "qualitative" aspect of experience is so important to inquiry. If one extends Bernstein's line of argumentation to include the importance of the qualitative, we have a much more stronger reason for why Pragmatism must not abandon experience. Without experience Pragmatism not only misses what constrains inquiry but much that guides and regulates it, in particular its qualitative dimension. According to Dewey and recent research on cognition, the qualitative accounts for the unity, continuity, coherence, direction, and self-regulation of inquiry.

In order to extend Bernstein's argument and defend the importance of experience for Pragmatism I need to take several steps. The central task is to outline all the important functions that, for Dewey, the qualitative has in inquiry. These functions are

\footnotetext{
13. Bernstein (2010: 134)

14. Bernstein (2010: 134)

15. Bernstein (2010: 134)

16. Bernstein (2010: 134)

17. Bernstein (2010: 52).

18. Bernstein (2010: 134)

19. Bernstein (2010: 134)

20. Bernstein (2010: 136)
} 
varied and crucial to our best inquiries. But before addressing the different functions of the qualitative in Dewey's view of inquiry, something must first be said about what Dewey means by the qualitative ${ }^{21}$. In the next section I briefly address some common misunderstandings about this notion, some responsible for the misdirected criticism of LCP to the classical pragmatists, that need to be cleared up before considering its several functions in inquiry. The sections that follow present the specific functions that the qualitative has in thinking (inquiry). I formulate nine such functions. Dewey mentions these functions at different places in his later works, but never in the positive, explicit, and systematic ways that they are presented here. Dewey had a much more radical but timely qualitative-embodied logic than has been appreciated. No other ideas distinguish Dewey more from the orthodox or mainstream view of thinking in philosophy, while also receiving so much support from recent research on the science of cognition. No other ideas make it so clear how different is the starting point between LCP and ECP. The essay concludes in the fourth section with some implications of these ideas to the current LCP and ECP debate.

\section{The Nature of the Qualitative}

Like the term "experience", the term "qualitative" has baggage or traditional associations that frustrated Dewey's effort to reconstruct philosophy. In philosophy quality is usually associated with either some abstract metaphysical property or some subjective or cognitive phenomena (as in sense data or qualia in consciousness), neither of which is Dewey's view. These traditional but still common views about qualities in philosophy are the result of starting with a theoretical picture of experience, one that is dualistic, instead of beginning with "experience as it is experienced" 22 , hence the importance already mentioned of the metaphilosophical commitment of Pragmatism. For Dewey qualities are experienced, they require an experiencer, but they do not belong to consciousness. They are found in situations and reveal aspects of nature. Qualities are not subjective, nor are they objective in the sense of being antecedent to experience ${ }^{23}$.

Qualities are context dependent, i.e., they have their "home" and meaning in a particular situation and may change or vary depending on the organism and the environment. This is true of all qualities. Color and sound are not qualities appreciated

21. The qualitative became Dewey's way of making sense of the notion of a situation, a notion central not only to his views on logic but also his entire philosophy. Regarding situations, Dewey asserted that without it his "view cannot be understood" (LW 14: 33), and that "almost everything I have written is a commentary on the fact that situations are immediate in their direct occurrence, and mediating and mediated in the temporal continuum constituting life-experience" (LW 14: 30).

22. This is Dewey's "postulate of immediate empiricism" (MW 3: 158-68). In Dewey's empirical starting point there is no dualism; the distinction between experiencing and what is experienced are two aspects of the integrity of lived experience.

23. The only sense in which Dewey says a quality is "intrinsic" or "objective" is in the sense that qualities are experienced as belonging to a thing as a "brute matter of space-time existence" (LW 15:43). In this sense, he states, "all qualities whatever are 'intrinsic' to the things they qualify at the time and place of the occurrence of the latter - provided only the things in question do genuinely 'have' them" (LW 15: 43). 
or discriminated in isolation, or self-sufficient elements that can be used to explain complex cases of sense perception. What is always experienced is the context of a situation as a scene of action, where what we are directly concerned with becomes focal and meaningful because of that implicit field. "When objects or qualities are cognitively apprehended, they are viewed in reference to the exigencies of the perceived field in which they occur" (LW 12: 153). However, the context in which particular qualities occur is itself qualitative since for Dewey there are tertiary qualities, i.e., qualities that pervade all the parts of a whole. This is key to Dewey's notion of a situation because the quality that pervades a situation is what demarcates it as a situation. A situation is a "complex existence that is held together in spite of its internal complexity by the fact that it is dominated and characterized throughout by a single quality" (LW 5: 246). To say that this quality "pervades" is to say that the quality runs through every aspect and detail of a situation, and that it gives meaning to each and binds them together. "If the situation experienced is that of being lost in a forest, the quality of being lost permeates and affects every detail that is observed and thought of" (LW 12: 203). In the following section we see how important these tertiary qualities are to a well-functioning inquiry.

The modern notion of experience reduces experience to experiencing, as a subjective cognitive state. This mistake, as well as the mind-body dualism and faculty psychology, has been responsible for the denigration or under appreciation of the function of what is qualitative (understood as emotions, feelings, passions) in thinking or cognition. The challenge we inherit from Dewey is how to talk about the qualitative without reifying the old dualisms between reason and passion, or between thinking and feeling. It is not easy to continue to use such terms and avoid dualistic connotations.

Even if many philosophers have abandoned the above dualisms in philosophy, they have continued to entertain intellectualist conceptions of thinking and intelligence. These are views that ignore the noncognitive qualitative context in which thinking occurs. Instead, they emphasize objects of knowledge, cognitive states, beliefs, propositions, reasoning, justification, and explanation. Insofar as LCP has continued this emphasis (and neglect), they belong to this same intellectualist tradition.

In the sciences there have been similar views under the name of "cognitivism" in which thinking is described in terms of "information procession models" 24 . However, this view has recently been challenged by what is called "embodied cognition" 25 . Empirical research on embodied cognition has exploded over the past thirteen years. These theories support Dewey's claims about the qualitative and thinking. Like Dewey, they do not start with the dualism mentioned but with a naturalistic starting point where as Mark Johnson explains, "body and mind are just different aspects of an ongoing interactional process of experience. Thus, the nature of our human bodies determines both what we can experience and think and also how we think, that is, how we conceptualize and reason" 26 . Embodied cognition theorists accept a radical view of embodied logic and meaning that emphasizes the role of emotions. According to

24. See Güzeldere 1998.

25. See http://plato.stanford.edu/entries/embodied-cognition/.

26. Johnson (2006: 46-54). 
Johnson, the work of cognitive neuroscientist Antonio Damasio has "opened the door to a serious reconsideration of James's claim [adopted by Dewey] that what we call logic requires an intact and functioning emotional system, and that our bodies play a crucial role in what makes sense to us and how we reason about it" 27.

What Dewey means by the qualitative includes and points to the dimension of our everyday experience that we call "emotions" or "feelings", but he is concerned that we do not ontologize or hypostatize emotions and feelings as entities independent of or antecedent to our direct qualitative experiences. This is why he says, "Experience is emotional but there are no separate things called emotions in it" (LW 10: 48). What we call emotions are things that we reflectively discriminate after we have certain immediate qualitative experiences. We identify anger as an emotion but "when angry we are not aware of anger but of these objects in their immediate and unique qualities" (LW 5: 248) $)^{28}$.

Perhaps the more difficult thing to understand about the qualitative is that it is experiences "had" and not cognitive or linguistic. In "Postulate of Immediate Empiricism" (1905), Dewey is already aware of how common and tempting it has been for philosophers to reduce, for example, the immediate experience of being frightened by a noise to "I knew I was frightened" or to some propositional description. An empirical philosopher must not concede this seemingly simple point to the critic. Theories of knowledge have tended to reduce immediate qualitative experience to something cognitive or linguistic, usually to a type of belief or perception, but this is not how they "are experienced as" 29 . The reduction of immediate experience to perception, as a form of cognition usually contrasted with conception, is assumed by LCP in much of the recent misdirected criticism of Dewey as succumbing to the "myth of the given", the notion that there is some nonconceptual epistemological foundation $^{30}$.

27. Johnson (2006: 46). See also Johnson 2010, and Damasio 2003. While this new research is exciting and important to those of us that agree with Dewey about the qualitative, we must not confuse or conflate a scientific theoretical explanation of how, as biological organisms, our emotions play a role in thought (which may include an evolutionary account of cognition and how our brains developed) with ontological claims about the qualitative (e.g., that primary experience is qualitative and felt).

28. Dewey issues the same warning about identifying the qualitative too closely with having a "feeling", even though it is about what is "felt": "If we designate this permeating qualitative unity in psychological language, we say it is felt rather than thought. Then, if we hypostatize it, we call it a feeling. But to term it a feeling is to reverse the actual state of affairs. Qualitativeness in the subject-matter defines the meaning of 'feeling'. The notion that 'a feeling' designates a ready-made independent psychical entity is a product of a reflection which presupposes the direct presence of quality as such" (LW 5: 248).

29. According to the postulate of immediate empiricism, "things are what they are experienced as" (MW 3: 158). As early as 1916 Dewey notes how phenomenologically insensitive philosophers tend to focus on a distinction obvious in experience: "The distinction between the two types of experience is evident to anyone who will take the trouble to recall what he does most of the time when not engaged in meditation or inquiry. But since one does not think about knowledge except when he is thinking, except, that is, when the intellectual or cognitional interest is dominant, the professional philosopher is only too prone to think of all experiences as if they were of the type he is specially engaged in, and hence unconsciously or intentionally to project its traits into experiences to which they are alien" (MW 10: 321).

30. Robert Brandom states, "Rorty and I both think that Sellars' critique of the myth of the given shows 
To be sure, Dewey does not assume a dualism between experienced had and the cognized. The latter, though different, is continuous with the former ${ }^{31}$. "Later one may (or may not) have an experience describable as I know-I-am...frightened. But this is a different experience"(MW 3: 162), one that is a result of inquiry. Some experiences "had" may end up having an important cognitive function in inquiry because, as we will see, they are funded by previous inquiries or lead to knowledge, but that does not change their ontological status of being, when they are experienced, as noncognitive. Dewey explains the mistake made by philosophers: "When, in a subsequent reflective experience, we look back and find these things and qualities...we are only too prone to suppose that they were then what they are now - objects of a cognitive regard, themes of an intellectual gesture. Hence, the erroneous conclusion that things are either just out of experience, or else are (more or less badly) known objects" (MW 3: 162).

More could be done on clarifying the ontological status of the qualitative ${ }^{32}$, but the above should be sufficient to avoid some common misunderstandings and serve as a background to the task ahead: outlining the functions that Dewey thought the qualitative have in inquiry and its implications.

\section{The Functions of the Qualitative in Dewey's View of Inquiry}

Dewey philosophical insights about the important functions of the qualitative in inquiry are scattered in his works, though most of them appear in Qualitative Thought (QT). One difficulty in sorting them out as I do here is that Dewey mainly writes about what happens if the qualitative is defective or fails to guide, instead of specifying the positive functions of the qualitative. This strategy makes sense, given that he is trying to make us aware of something about our experience of thinking that is so taken for granted. The consequences of lack of control of the operations of inquiry (e.g., observation, reasoning) by the qualitative are confusion, incoherence, arbitrariness, the mechanical, lack of logical force, and leaving relations unexplained. However, making explicit the positive functions of the qualitative seems a worthwhile task. First, it makes more evident the centrality of Dewey's view on the qualitative in his views on inquiry, and in particular his logic. Second, and relevant to the main argument in this paper, it makes clear what is at stake for Pragmatism if it gives up on experience: a robust view of inquiry.

the notion of experience as simply outmoded...I agree with him that there is no useful way to rehabilitate the concept of experience. We just need to do without that" (interview with Robert Brandom, Filosofisk Supplement, 5). Scott Aikin claims that Dewey relied on noninferential and nonconceptual content or givens as perceptual inputs for cognitive experience (2009: 19-27). According to Koopman, "To avoid this foundationalism...contemporary pragmatists who are eager to revive the concept of experience must be on guard to not treat experience as a kind of ultimate given-ness against which we might be able to measure our truth claims" (2007: 696-97).

31. Moreover, as we will soon explain, the cognized is within a qualitative situation "had" as its context or background.

32. In Experience and Nature Dewey translates the difference between had and cognitive experiences in terms of two basic traits that can be attributed to nature: nature in its finalities (or consummations) and in its relations (LW 1: 82). 
At the end of QT Dewey summarizes his main thesis very well: "The immediate existence of quality, and of dominant and pervasive quality, is [a] the background, [b] the point of departure, and [c] the regulative principle of all thinking" (LW 5:261) ${ }^{33}$. In truth, each of these broad functions $[a, b, c]$ received a much detailed specification in the later works of Dewey. Lets unpack all the functions.

\section{[a] "the background"}

$i$. The qualitative as the background that unifies and demarcates the situation in which thinking occurs

The notion that the qualitative functions as the background of thinking has already been addressed or implied in the idea that knowledge is just one mode of experience located within experience at large, and in the distinction between experiences had and cognized. Dewey states that "the background, the thread, and the directive clue in what we do expressively think of...is 'felt' rather than thought" (LW 5: 248). The qualitative is what characterizes our pretheoretical and precognitive experience in the world. A qualitative world of persons and things is the most basic and inclusive context in which one finds language, knowledge, and all of our more discursive activities, including philosophy. "The universe of experience surrounds and regulates the universe of discourse but never appears as such within the latter" (LW 12: 74). However, there is no qualitative experience at large that makes the background of discourse-thinking; there is always a specific situation. Thinking arises from within and emerges out of the pervasive qualitative situations that make up the moments of our lives. All thought is situated, embodied, and interfused with feeling.

In his philosophical career Dewey struggled to make sense to others of his important notion of a "situation" 34 . A particular situation is demarcated by an experienced unifying quality, and each situation is unique. You can describe and have a theory about situations, but these forms of discourse point to something that is experienced. This sounded (and still sounds) mysterious or contradictory to philosophers who assume the ubiquity of knowledge or language (discourse) in life.

Dewey's frustration with Russell on this issue is obvious in these passages:

M. Russell has not been able to follow the distinction I make between the immediately had material of non-cognitively experienced situations and the material of cognition a distinction without which my view cannot be understood. (LW 14: 33)

33. I have added the [ ] in the above quotation because there are actually three different claims made here about the qualitative. Dewey does not separate them, nor has Dewey scholarship considered them separately as I do.

34. Dewey did not abandon the importance of the correlated notions of situations and the qualitative to his philosophy even after the publication of QT. In the recently published Unmodern Philosophy that Dewey wrote in 1945, Dewey stresses in the last chapter how "everything inquired into and discussed belongs in a field or situation" (2012: 334), and how "qualities...characterize the matter of first hand experience"(2012: 334). In fact, Dewey repeats almost the same central thesis of QT: "Every case of knowing begins and ends with and in situations and is regulated all the way through in its capacity as a transition from one situation to another" (2012: 342; emphasis mine). I will later show why for Dewey regulation of thinking by a situation is synonymous with regulation of thinking by the qualitative. 
Any one who refuses to go outside the universe of discourse - as Mr. Russell apparently does - has of course shut himself off from understanding what a "situation", as directly experienced subject-matter, is. (LW 14: 31$)^{35}$

Dewey understands the force of the objection that we must use language to refer to what is presumably nonlinguistic: "It would be a contradiction if I attempted to demonstrate by means of discourse, the existence of universes of experience". But he offers this reply, which clarifies his view: "It is not a contradiction by means of discourse to invite the reader to have for himself that kind of immediately experienced situation in which the presence of a situation as a universe of experience is seen to be the encompassing and regulating condition of all discourse" (LW 12: 75).

For Dewey, a situation is in the background as context and always remains there. One cannot "decline to have a situation for that is equivalent to having no experience" (LW 12: 74). To some extent, the experience of a unifying quality of a situation defies description, for as soon as we describe it we are making discriminations regarding a situation that was once felt while we are in a new situation that cannot be stated and made explicit. In other words, quality is ineffable in that it cannot be objectively denoted in such a way that it is not embedded in another experience (a situation) with its own quality.

This claim about ineffability is bound to make LCP and all twentieth-century philosophers who are committed to the linguistic turn in philosophy suspicious that Dewey is committed to some mysterious metaphysical domain. It is one reason why a neopragmatist like Robert Brandom thinks it would be best for Pragmatism to abandon the notion of experience since thinking is only embedded in "linguistic practices"36. However, Dewey was puzzled as to why philosophers believed his claims about the ineffable aspect of experience commit someone to any mysterious domain. He says, "The word 'experience' is, I repeat, a notation of an inexpressible as that which decides the ultimate status of all which is expressed; inexpressible not because it is so remote and transcendent, but because it is so immediately engrossing and matter of course" (MW 10: 325).

According to Mark Johnson, "One of the most earth-shattering discoveries to come out of the cognitive sciences over the past three decades is that human thinking and willing operate mostly beneath the level of our conscious awareness" ${ }^{\prime 37}$. This is unsettling for philosophers today, but it was key to the view of experience of William James and Dewey. The received Enlightenment view of thinking as a conscious reasoning process is for Dewey only one aspect of what occurs at the foreground of thinking. When we think at the foreground, we discriminate objects, patterns, and relations, but beneath such fruits of reflection there is a felt experience of a pervasive unifying quality of the entire situation that one is inhabiting. This unity is precisely

35. M. Russell is so wedded to the idea that there is no experienced material outside the field of discourse that any intimation that there is such material relegates it, ipso facto, to the status of the "unknowable" (LW 14: 33).

36. Brandom (2011: 26).

37. Johnson (2014: 114). 
the situation that one is in. Critical to this view is the existence of the tertiary qualities already mentioned, i.e., qualities that pervade entire contexts ${ }^{38}$.

This general idea that there is a larger unity or context that unifies and makes meaningful the parts so that without it the parts are not a unity nor meaningful is not new. Twentieth-century philosophy of language and epistemology has moved beyond the atomistic view that meaning and truth are properties of a single word and belief to the more holistic view that particular words and beliefs can only be meaningful because of the broader context of a language, a "web of beliefs" or "conceptual schemes". What is radical about Dewey is that all of these larger contexts are unified and meaningful because of what is not discourse and is very particular: a unique and qualitative situation. Dewey writes, "Discourse that is not controlled by reference to a situation is not discourse, but a meaningless jumble, just as a mass of pied type is not a font much less a sentence" (LW 12: 74).

\section{ii. The qualitative as the background that gives continuity to thinking}

Since inquiry is a process, the unity provided by the qualitative as background is also temporal, that is, it provides a needed continuity without which inquiry could easily be diverted. The qualitative therefore functions as the underlying "thread" and "directive clue" (LW 5: 248) of what is explicitly thought about. Inquiry begins with a situation that has the tertiary quality of being indeterminate, but is soon experienced as "problematic", that is, as reflecting on answering the question "what is the problem?". At this point, Dewey says, "to mistake the problem involved is to cause subsequent inquiry to be irrelevant or go astray" (LW 12: 112). For Dewey, it is the qualitative that guides the inquirer in knowing whether he/she is still dealing with the same problem or is venturing into a different one. Dewey explains how "feeling" the problem is what protects us from "leaps" or diversions in the process of inquiry. Attention to the continuous but changing feeling is what "enables us to keep thinking about one problem without our having constantly to stop to ask ourselves what it is after all that we are thinking about. We are aware of it not by itself but as the background, the thread, and the directive clue in what we do expressly think of. For the latter things are its distinctions and relations" (LW 5: 248).

The background functions of the qualitative in thinking that we have outlined are the least radical claim in the above summary thesis of Dewey in QT. Even the most intellectualist of philosophers can easily acknowledge that there is a background

38. Dewey does not have an argument to show that there are such qualities. All he does, and perhaps all he can do, is appeal to the reader's experience. In QT he uses examples in the experiences of the arts. The experience of pervasive quality is how we immediately identify or distinguish, for example, a Picasso from a Matisse. "A man sees a picture and says at first sight that it is by Goya or by someone influenced by him. He passes the judgment long before he has made any analysis or any explicit identification of elements. It is the quality of the picture as a whole that operates"(LW 5: 251). Similarly, beneath or encompassing the rich variety of things found in a thinking event in which we partake, there is a single quality that pervades the entire experience. When we are engaged in thinking about a particular scientific problem or any ordinary problem, there is an all-encompassing way that it feels and "colors" all the things we recognize or discriminate that is unique to that moment in your life and that demarcates it from other events. Dewey warns that "this unity is neither emotional, practical, nor intellectual, for these terms name the distinctions that reflection can make within it" (LW 10: 44). 
surrounding discourse that is nondiscursive and nonlinguistic. The more controversial claims in Dewey's thesis are the next two clauses: that the qualitative is also "the point of departure", and that it is "regulative".

[b] "The point of departure"

iii. The qualitative motivates, gives the initial sense of direction to and material for inquiry, and is a condition for the emergence of genuine thinking

While this statement mentions four different functions of the qualitative, I address them together since they all address inquiry at its inception or point of departure. The less controversial of these functions is that the qualitative is the starting point in the sense that it motivates ("sparks" or "triggers") inquiry. In fact, this has been one the most common traditional views about the function of the qualitative, usually understood as our passional-affective nature: it is what drives the intellect (or reason), but once inquiry is on its way the qualitative plays no cognitive function. But this is hardly Dewey's view.

While all thinking is embedded in a qualitative context, only a qualitative context of a particular mode, indeterminate, makes thinking emerge from the stream of life. Situations that demand reconstruction through inquiry are situations that are qualitatively experienced as unsettled, confused, and indeterminate. The transformation of the pervasive quality of this sort of situation is, in effect, the general function of inquiry. The indeterminate situation is at first precognitive - "A problem must be felt before it can be stated" (LW 12: 76) - but it is soon experienced as "problematic", that is, as reflecting on answering the question "what is the problem?"39.

Experiencing the situation as problematic or requiring inquiry is the initial step in inquiry but it arises from a precognitive indeterminate situation that is not a subjective or mental state or a confused cognitive state 40 ; Moreover, Dewey stresses that its qualitative indeterminacy is unique and cannot be ignored or passed over by an inquirer since however unstable or confusing the situation may feel, it is through it and by it that we receive any empirical guidance as to where to go next in inquiry. In other words, even when the qualitative is functioning as a point of departure, it is a departure that already provides a much-needed point or sense of direction as to where to go - it is already exercising a "regulative" function. Dewey says, "It is this unique quality...that exercises control over its special procedures...Unless a situation is uniquely qualified in its very indeterminateness, there is a condition of complete panic; response to it takes the form of blind and wild overt activities" (LW 12: 109). Scientific inquirers, no matter how theoretical or abstract their problems may be, begin with and take seriously their qualitative starting point, i.e., the unique indeterminacy that is felt.

39. One phase merges into the other but must not be confused. "The unsettled or indeterminate situation might have been called a problematic situation. This name would have been, however, proleptic and anticipatory. The indeterminate situation becomes problematic in the very process of being subjected to inquiry. There is nothing intellectual or cognitive in the existence of such situations, although they are the necessary condition of cognitive operations or inquiry" (LW 12: 111).

40. He stresses that "it is the situation that has these traits, We are doubtful because the situation is inherently doubtful" (LW 12: 109). 
If there is not enough of a problem grounded in these qualitative experiences inquiry lacks more than a spark, it lacks a sense of where to go.

About the indeterminacy experienced at the start of or preceding inquiry, Dewey says in QT: "In itself, it is the big, buzzing, blooming confusion of which James wrote. This expresses not only the state of a baby's experience but the first stage and background of all thinking on any subject. There is, however, no inarticulate quality which is merely buzzing and blooming. It buzzes to some effect; it blooms toward some fruitage. That is, the quality, although dumb, has as a part of its complex quality a movement or transition in some direction. It can, therefore, be intellectually symbolized and converted into an object of thought" (LW 5: 254; emphasis mine).

The notion that a noncognitive and immediate quality can become or be the seed of intellectually symbolized subject matter or objects of thought may seem strange to someone with different metaphysical assumptions or may seem like Dewey is presupposing a dualism, but the view is that there is continuity between two kinds of experiences. He states, "when it is said that a thing cognized is different from an earlier non-cognitionally experienced thing, the saying no more implies lack of continuity between the things, than the obvious remark that a seed is different than a flower" (MW 3: 166). Our more reflective judgments (the flower) emerge from within the same initial qualitative experience (the seed) that provoked it. Moreover, what occurs is not a total displacement of one kind over the other, i.e., from the qualitative to the purely symbolic or cognitive. Even the most symbolic, cognitive propositional is contained within a qualitative context, a context that participates (contributes) to the development of the process even if it is not in the foreground or even addressed in our explicit justifications and explanations.

\section{$[c]$ "The regulative principle of all thinking"}

One could agree that the qualitative (as a felt situation) is in the background and the starting point of all thinking, but also claim that once discourse is on its way its development or regulation is independent of the felt dimension of experience. This is not Dewey's view. As soon as reflection gets started in any of the events in which we think, we make discriminations and engage in the operations of inquiry, but even when it is in the background, as it is in the sciences, the qualitative operates by regulating, controlling the process of inquiry.

The following are specific ways mentioned throughout several of Dewey's later works in which the qualitative exerts a regulative function in inquiry.

\section{iv. The qualitative as "intuition" that precedes reflection and functions as} funded experience

In inquiry, reflective activities such as reasoning, discrimination, analysis, inferences, reason examination, and justification are preceded by a qualitative assessment that can be called "intuition". Dewey claims that reflection is often "ideational and conceptual transformation of what begins as an intuition" (LW 5:249). Dewey is well aware of the problem with the word "intuition". He does not mean a 
faculty or a type of knowledge; it is simply an immediate qualitative judgment that is functionally different from those later in the same inquiry that are considered more reflective or preceded by reflection.

Reflection and rational elaboration spring from and make explicit a prior intuition. But there is nothing mystical about this fact, and it does not signify that there are two modes of knowledge, one of which is appropriate to one kind of subject-matter, and the other mode to the other kind...Intuition, in short, signifies the realization of a pervasive quality such that it regulates the determination of relevant distinctions. (LW 5: 249)

When we are in a problematic situation we start with immediate unreflective qualitative judgments that precede the more definite recognition of which particular features of the situation confirm or go against our judgment. We engage in analysis, survey, and reasoning in order to examine (test) or revise this preliminary reaction. The overwhelming first impression comes first; it changes as inquiry proceeds, and it serves to guide the subsequent phases of analysis and discrimination. Dewey explains how all inquiry starts with a "hunch" or "impression", but this is not something psychical or psychological. It is the presence of a dominant quality in a situation as a whole.

To say I have a feeling or impression that so and so is the case is to note that the quality in question is not yet resolved into determinate terms and relations; it marks a conclusion without statement of the reasons for it, the grounds upon which it rests. It is the first stage in the development of explicit distinctions. All thought in every subject begins with just such an unanalyzed whole. (LW 5: 248-249)

The view that intuition precedes reasoning (reason giving and justification) has received considerable support in recent research in social psychology and cognitive science. Psychologists Hauser and Haidt have presented a model of moral cognition in which judgments are primarily intuitive, "gut-level", emotionally guided evaluations that occur prior to explicit reasoning or deliberation ${ }^{41}$. "Intuition...is the main cause of moral judgment....and then reasoning typically follows that judgment...to construct post hoc justifications" 42 .

For Dewey the model of thinking suggested by this recent research is true of all thinking, not just moral cognition. This reversal of the traditional function of reasoning may seem like Hume's view that the intellect is at the mercy of the passions, but some qualifications are necessary to avoid confusing it with the Humean view or with what we usually call "rationalizations". First, for Dewey there is no dualism between intuition and our more reflective judgments. On the contrary, there is continuity and in proper inquiry one ensues on the other. Second, while the qualitative as intuition starts and guides explicit reasoning or articulated propositional thought, it is itself transformed in the process by reflection. Third, even though our first intuitions are immediate, qualitative, and noncognitive, they are funded by previous experience.

41. Hauser 2006. See also Hauser, Young, and Cushman (2008: 107-143).

42. Haidt (2012: 46). See also Haidt (2001: 814-34); Green and Haidt (2002: 517-23); Haidt (2007:

998-1002); Haidt and Joseph (2004: 55-66); and Haidt 2006. 
This is why they are such an important resource to inquiry. Dewey claims that sometimes our immediate experiences of pervasive quality have "intellectual import" because they are not mere immediate responses; they are well funded, i.e., they "sum up and integrate prolonged previous experience and training, and bring to a unified head the results of severe and consecutive reflection" (LW 5: 250).

Sometimes our intuitions are so well funded by previous experience and reflection that they are the source of brilliant thinking. However, as we know, intuitions can at other times be funded with malignant prejudices or narrow perspectives. There is no way to find out a priori which ones are which. Nevertheless, experimental thinking needs to start where we are or with what we have. Different individuals and communities start with different intuitions. Hopefully, inquiry and criticism will reveal whether they are to be questioned or transformed, but there is no Archimedean standpoint where intuitions can be examined, nor is there a reflective standpoint that is not itself guided by an immediate qualitative of a situation.

For Dewey the view that judgments and evaluations are reached by reasoning (with premises and rules in propositional form) is a theoretical-abstract explanation that we can devise after we make actual judgments and decisions. They are not how the most competent inquirers experience these situations. This is the case in all areas of our lives where judgment is required. Good scientists, trumpet players, and cooks may formulate the basis of their judgments in a set of rules or criteria, but this is done for the purposes of the novice; it does not come into their experience ${ }^{43}$.

For Dewey the demand for reasons and justification is not a function of reason but something that emerged socially. "It is quite conceivable that if no one had ever had to account to others for his decisions, logical operations would never have developed, but men would use exclusively methods of inarticulate intuition and impression, feeling; so that only after considerable experience in accounting for their decisions to others who demanded a reason...did men begin to give an account to themselves of the process of reaching a conclusion in a justified way"(MW 15: 73). Articulating in propositional form what traits or features of a situation sustain one's judgment is key to justifying ourselves to others, and to invite them to consider the situation for themselves. In other words, it facilitates a more communal inquiry and it may lead to a change in the overall qualitative judgment of what is correct as inquiry proceeds.

Our intuitions are usually the result of what habits have been developed from previous experience. However, Dewey does not limit the function of the qualitative to bringing to bear past funded experience on present experience. This is important to distinguish his view from other contemporary views. Some twentieth-century philosophers have given the qualitative (as either "gut feelings", "emotional reactions of "yuk" "44, or "intuitions") some guiding role in deliberation, but it clearly plays a subordinate role in more ways than one. For example, when gut feelings are determined to have some weight it is because they are conceived as or reduced to

43. See "Logical Method and Law" (MW 15: 65), Dewey distinguishes "vital logic" from the "logic of exposition".

44. See http://philosophybites.com/2009/03/julian-savulescu-on-the-yuk-factor.html 
habits or some useful form of intuitive social knowledge ${ }^{45}$. They are given some function in deliberation because they are conceived as, at best, disguised (embodied) crude rules of thumb that have served us in the past. Nevertheless, they are useful only at the beginning of inquiry and are inept in dealing with the complexity and nuances of particular situations. We have to rely on them because, unfortunately, we don't have time for reflection in many situations. For example, it is a good thing that most of us have an immediate "feeling" regarding incoherence, danger, and injustices, but nothing replaces deliberation by reason. In an ideal world, a world without limitations on time to make well-reasoned decisions, we would not need to rely on the qualitative. This is not Dewey's view.

Dewey agrees that because immediate experience is funded we have good reason to trust the gut feelings of the experienced few on some subjects; however, for him the function of the qualitative is not limited to lessons from the past, it is also what guides the present operations of inquiry in light of the present situation that is being transformed as it is transformed. To put it crudely, we "feel" the present situation as we think so that, contrary to the above view, we often need the qualitative to assess the complexity, uniqueness, and nuances of particular situations. The particular details of a situation or what operations are relevant are determined by being sensitive to the present context of inquiry. In other words, guiding ourselves by the qualitative in a situation amounts to more that just guiding ourselves by our habits. A skilled scientist or jazz musician certainly responds automatically (habitually to certain cues in experience). There is a know-how that is the result of previous experience, but there is also a response to the unique qualitative guidance of the situation as it develops. The present situation sometimes guides in ways that are not reduced to previously found know-how. The richness of present qualitative experiences and its instructions for us are not always reduced to the conditions of what we bring from past experiences.

v. The qualitative determines the relevance and weight of distinctions, facts, concepts, and principles in inquiry

In inquiry the search for the reasons that ground our overall impression or intuition must be a sincere survey of how the relevant features that make up a situation are related, and it may lead to assertions or propositions to be tested. However, how do we determine what features are relevant in a particular inquiry and how much weight should they be given relative to others? The answer is by being sensitive to the quality of the situation.

The qualitative has the important function of guiding inquirers in their immediate sense of what is relevant and irrelevant as inquiry proceeds. In QT Dewey says, "The underlying unity of qualitativeness regulates pertinence or relevancy and force of every distinction and relation" (LW 5: 249); and, in the Logic, "without its controlling presence, there is no way to determine the relevancy, weight or coherence of any

45. This is the view of our immediate emotional intuitions that is assumed by, for example, Hare 1981. This view is also explained in "Julian Savulescu on the 'Yuk' Factor" available at: http:// philosophybites.com/2009/03/julian-savulescu-on-the-yuk-factor.html. 
designated distinction or relation" (LW 12: 74). In Art as Experience he claims that emotion is not just the moving force of inquiry but the "cementing" that "selects what is congruous and dyes what is selected with its color, thereby giving qualitative unity to materials disparate and dissimilar" (LW 10: 44).

Sensitivity to the quality of a situation is crucial in determining the relevance of our rules and principles in any inquiry. "The situation controls the terms of thought; for they are its distinctions, and applicability to it is the ultimate test of their validity" (LW 5: 247). No matter how good or true our propositions or principles are, "there is no label, on any given idea or principle, that says automatically "use me in this situation" (LW 8: 215). The direct tact and discernment of a good judge in any type of inquiry is not a matter of being equipped with information. No rules can replace the power to seize the significant factors in a situation and the sensitivity to the quality of the problematic situation that is being transformed.

\section{vi. The qualitative provides guidance in selection and rejection}

Determining relevance and weight in inquiry is usually a means of deciding what to select and reject as inquiry develops, therefore the qualitative is also key to these operations. Dewey says that the qualitative "guides selection and rejection and the manner of utilization of all explicit terms" (LW 5:249), and that "the selective determination and relation of objects in thought is controlled by reference to a situation - to that which is constituted by a pervasive and internally integrating quality, so that failure to acknowledge the situation leaves, in the end, the logical force of objects and their relations inexplicable" (LW 5: 246). The consequences of not regulating inquiry by the qualitative can be what we usually call scattered thinking and incoherence. In some forms of inquiry the qualitative accounts for the "intellectual definitiveness" and "coherence" of the objects of a thought 46 .

vii. The qualitative guides the proper relation and proportion between the operations of inquiry

In the Logic, Dewey distinguishes between observation, fact gathering, perception, conception, reasoning, and ideas as different operations that exercise different functions in inquiry. He does not, however, describe exactly what the ideal relation should be between these operations beyond the claim that they need to mutually affect each other in the process. However, it is clear from the following passage that he holds that many defects in thinking are the consequence of one of the operations exercising too much control over another. Dewey's solution is also clear: let sensitivity to the qualitative situation as a whole regulate how much, for example, observation and conceptual ordering should relate to one another.

It is more or less a commonplace that it is possible to carry on observations that amass facts tirelessly and yet the observed "facts" lead nowhere. On the other hand, it

46. "Such intellectual definiteness and coherence as the objects and criticisms of esthetic and moral subjects possess is due to their being controlled by the quality of subject-matter as a whole. Consideration of the meaning of regulation by an underlying and pervasive quality is the theme of this article" (LW 5: 246). 
is possible to have the work of observation so controlled by a conceptual framework fixed in advance that the very things which are genuinely decisive in the problem in hand and its solution, are completely overlooked. Everything is forced into the predetermined conceptual and theoretical scheme. The way, and the only way, to escape these two evils, is sensitivity to the quality of a situation as a whole. In ordinary language, a problem must be felt before it can be stated. If the unique quality of the situation is had immediately, then there is something that regulates the selection and the weighing of observed facts and their conceptual ordering (LW 12: 76).

viii. The qualitative as the control-guidance provided by phases of undergoing and synthesis of all experimental inquiries

The above functions of the qualitative need to be understood as integral to a larger and complex process. In any process of inquiry we can make a functional distinction between phases of doing and undergoing as well as phases of analysis and synthesis ${ }^{47}$. These phases are mutually dependent and are what make inquiry a cumulative undertaking that can guide itself to some final judgment. The qualitative is responsible for the undergoing and synthesis phases that regulate the doing and analysis. Analysis is what we do when inquiry is centered on making some finer discrimination of the parts that make up our problematic situation. Synthesis takes place when we are concerned with weighing how the parts contribute to the making of overall judgments.

The final judgment in any inquiry is a synthesis that results from the analysis of the situation as a whole, but it is only the final step in a series of tentative overall judgments that have occurred throughout the entire process of deliberation. This same process can also be described in terms of the phases of the doing and undergoing of any mundane experimental learning process. The doing might be acting to gather more evidence or the active operations of recollection and exploration. Undergoing occurs in the form of a constant receptivity to what is revealed by our doings (e.g., testing a hypothesis) or the reactions of others engaged in the process.

\section{ix. The qualitative guides judgment: Dewey's contextualism}

In philosophy, because of the linguistic turn, judgments are often treated as or simply equated with propositions or as an aspect of discourse But for Dewey a judgment is not a proposition ${ }^{48}$, a judgment is a practical act, affirmation, or assertion that "in distinction from propositions which are singular, plural, generic and universal, is individual, since it is concerned with unique qualitative situations" (LW 12: 283; emphasis mine). Dewey was a contextualist in regard to judgment. His contextualism is radical since what ultimately guides and warrants our judgments are not the shared standards of a community nor the most stable inherited norms, however useful and binding these resources may be, but the individual unique qualitative situation that we are in. In his contextualism the control and guidance provided in inquiry by context is provided in part by the underlying and pervasive quality of the situation that is

47. These are distinctions that Dewey made about inquiry in his more educational texts, such as "How We Think" (MW 6).

48. For more on this important tenet of Dewey, see Burke 1994. 
being transformed. To be sure, propositions in inquiry are tested by their coherence with other propositions as well as the result of operations with inquiry (observation, reasoning, and so on) but applicability of the final judgment to the problematic situation is the ultimate test of its validity.

In inquiry the agent is engaged in a process of continually shaping and reshaping (doing and undergoing) until she qualitatively appreciates that the proposed solution meets the demands or problems presented by the developing situation that has been explored. When this happens a judgment is warranted, but this is experienced as an immediate quality of determinacy that can be described as a fittingness or appropriateness to the situation. In other words, the final judgment is the qualitative appreciation and assertion that, in light of the terrain explored, this is the solution that is called for by the situation, and not a deduction from propositions or from a universal criterion. To acquire the habits capable of making these kinds of context-sensitive judgments is to have intelligence. Notice what this entails. The qualitative instructions that tell whether one has come close to fulfillment in inquiry are not to be found outside of the particular unique qualitative situation that is experienced as needing transformation. "The making comes to an end when its result is experienced as goodand that experience comes not by mere intellectual and outside judgment but in direct perception" (LW 10: 56). The situation itself can give the agent a pervading qualitative sense of relevance and satisfactory closure during the process of reconstruction.

The above contextualism is assumed in Dewey's Logic. Without it one misses an important restraint, control, or guidance that he takes for granted in his presentation of the structure and operations of inquiry. Without it his view of inquiry seems vulnerable to the charge that his view is not robust enough to account for how, without presupposing some universal criteria or standard of truth, inquiry can arrive at justified belief. Critics of Dewey cannot understand how his empirical approach to inquiry, one that denies the absolute and a priori character of logical forms, could have enough normative force or constraints to avoid laxity or relativism in matters of inquiry. The following reply of Dewey applies to many of his critics: "The source of Russell's misconception of my view is his imperviousness to what I have said about the problematic quality of situations as giving both the occasion for and the control of inquiry" (LW 14: 33, emphasis mine).

Appreciating the function of the qualitative in Dewey is important for appreciating how he reverses the order of where normative-regulative force comes from. Philosophy has been very top down on this issue. It is common to assume that the normativity or reasonableness of particular judgments is solely derivative from general rules. For Dewey, this is backwards and puts the emphasis on the wrong place. Judgments are individual acts and are concerned with a unique qualitative context. Rules, criteria, standards, and reasons are instrumentalities that ultimately derive their validity from particular judgments, even though after many successful inquiries, and because of their success, they acquire their own normative force. As was previously said, the wiser among us rely on these instrumentalities only when one's habitual response to situations is not sufficient, or after a judgment in order to justify oneself or invite others to consider the situation for themselves. 


\section{Conclusion}

I have outlined nine functions of the qualitative in inquiry in order to show the difference that experience has made to Pragmatism in the study of human thought and inquiry. For ECP it was experience as a methodological commitment (in its critical, preventative, and edifying functions) that enabled Dewey to criticize the modern view of knowledge and thinking as a capacity of reason. It was experience that enabled him to avoid the dualisms, reductionism, and intellectualism that are so common and tempting in epistemology-logic. More importantly, it was because of experience that he was able to provide such a rich view of inquiry. He foresaw what recent scientific accounts of human thinking have confirmed: it is more bodily based, non-linguistic, complex, messy, and less linear than philosophers have assumed.

As a reaction to the modern notion of reason, many twentieth century philosophers (including LCP) has stressed the historical, social, and linguistic aspects of thinking, but often at the expense of the role of the qualitative in thinking. While the qualitative is not all there is to thinking, it seems to be part of what would be questioned or given up if we followed the advice of LCP and eliminated experience.

None of this will likely convince LCP nor refute his/her approach to Pragmatism,

but it makes clear what, from the point of view of ECP, is at stake in eliminating experience. It also serves to highlight how significant are the differences between these two types of pragmatists. It will not facilitate future dialogue if LCP continue to misdirect their criticism of experience to the traditional modern notion and also neglect the particular metaphilosophical functions of experience that I have outlined at the beginning of this paper. To be sure, LCP may disagree about these functions or suggest that experience is not the best means to accomplish them in philosophy, but this would be an improvement over the present lack of confrontation of our deeper differences.

Dewey, of course, recognized the linguistic context of inquiry but this is simply not all there is to context $\mathrm{t}^{49}$, contrary to LCP we are not just embedded in "linguistic practices" 50 . For Dewey, the idea that I am in a situation that is had in some precognitive way strikes him as more concrete and obvious than saying that I am in a "practice" as a "language game" (or anything linguistic), which seems more of an abstraction or a description of everyday life from a theoretical point of view. Nothing could be more contrary to the metaphilosophical commitment to experience than for philosophy to start with a theoretical view of things. If LCP starts with the theory that all lived experience or practice, including our inquiries, are discursive all the way down, then from the point of view of ECP this is as problematic as the dualistic starting points of modern philosophy. For ECP the recognition that there is a qualitative aspect of context that is non-linguistic (and even ineffable) does not commit them to the existence of a mysterious domain or a problematic epistemic given. It is just to

49. Dewey would argue that to think that language is all there is to context is to commit the philosophical fallacy. We can discriminate the perhaps unavoidable and important linguistic component of our lived situations, but to then proclaim that it is all language is fallacious.

50. Brandom (2011: 26). 
acknowledge the embodied and "felt" character of all of our activities, including the most abstract thinking. And as I have argued, the sciences continue to confirm that the context that guides inquiry is embodied and "felt" and not linguistic.

LCP could reply that they are not denying that there is a nonlinguistic aspect to life, but simply that it is not that important. But this is precisely what the above functions of the qualitative refute. The function of the qualitative is not, as traditionally thought, limited to what causes or motives ("sparks" or "triggers") inquiry. For ECP what surrounds the linguistic and cognitive is not tangential to what is discursive, it plays several guiding roles in all of the operations and phases of inquiry. Inquiry is, of course, social and linguistic, but without the above functions of the qualitative the pragmatist account of inquiry seems to lack not only friction or constraints, as suggested by Bernstein, but a robust enough view about the regulation of inquiry.

ECP also finds it difficult to give up on experience because the alternative approach of LCP has so far left the pragmatists view of inquiry vulnerable to some problems. These are the consequences of LCP (and their elimination of experience) that concerned Bernstein. I share this concern and have extend and strengthen Bernstein's argument about why the classical pragmatists valorize experience in relation to inquiry and why we must continue to do so.

Bernstein is correct to point out that for the classical pragmatists experience meant brute compulsiveness (what Peirce calls "secondness"), but just as important is its qualitative character (what Peirce calls "firstness"). Acknowledgement of the qualitative aspect in any inquiry is required to make sense of how inquiry can regulate itself without the need of foundations outside of experience, but also without sliding into the linguistic relativism of LCP. The danger of the LCP view of inquiry is that there seems to be nothing that regulates language except more language.

While secondness accounts for the "brute constraint" of our inquiries, or the idea that there is a natural-environmental "grain of things" that humans need to respect, the qualitative accounts for how inquires are able to guide themselves in the process of inquiry. This is not a small addition to Bernstein's line of argumentation. It is one thing is to claim that everyday situational experience does not let us think what we want, and another that it can guide us if we are ready to listen. The secondness accounts for why we need to be open and fallible, since experience can surprise us, but the qualitative accounts for why we need to be sensitive to our doings in inquiry. If with secondness experience "says $\mathrm{NO}^{51}$ and shows the limitations of language, with the qualitative experience says "YES and NO" insofar as it is a key force in guiding concrete inquirers in their transformation of an indeterminate situation to one that is determinate. The nine functions of the qualitative outlined in the previous section means that for Dewey without the qualitative we cannot account for the unity, continuity, coherence, direction, and self-regulation of our best inquiries.

Dewey's ultimate grounding is a historical and contextual one, but the appeal to context is not just to discourse, community standards, or consensus. These things are important but they are part of a situation. If a problem has a solution it must emerge

51. Bernstein (2010: 134). 
from guiding our inquiry by its initial direct and unique problematic character. It is not true that without some external criteria of truth or validity we are lost and cannot transform the situation. Dewey appeals to a faith in our transactions within nature, that is, within a situation that can guide our judgments. The context is a qualitative situation; its guiding does not entail foundationalism and it makes the nonlinguistic important in ways denied by LCP.

I have not, of course, in this paper challenged LCP on their own ground, though I have presented to him/her a challenge based on what I take to be a common ground: if you are a pragmatists, then show us the difference that preferring language over experience makes in doing philosophy, and in particular in the notion of inquiry.

LCP is not devoid of providing some reasonable replies to the challenges or questions I have presented. Lets consider even if briefly some possible replies they could make on behalf of eliminating experience and adopting a linguistic approach.

I have argued that the account of inquiry inherited by the classical figures (one that is tied to their notion of experience) is worth reconstructing because it makes sense of our own experience of some common features of our best inquiries (e.g., its immediate experiential constraining and guiding quality) and it is receiving much support from recent research on the science of cognition. However, LCP can always reply that they can also muster empirical evidence for their view or that they are simply not interested in being empirical, at least in the same sense that the classical figures were.

LCP could also argue that they can achieve the exact same fruits, a rich and empirical notion of inquiry, without invoking experience and without the need to abandon their linguistic center view of thinking. Someone like Brandom, for instance, may find ingenious way to accommodate for the qualitative (and its functions) in his view by distinguishing between his preferred assertoric uses of language and more emotional or expressive uses, but to this day he doesn't have a fully developed view about the role of emotions in inquiry or in guiding practical dealings with one another. In any case, it is not clear how starting from his theoretical picture of practice as discursive can Brandom account for the embodied nature of human cognition and activities. As Steven Levine has argued, Brandom's Pragmatism "remains immanent to the realm of the discursive. But this makes it impossible for him to understand a richer sense of practice that is often at work in the classical pragmatists, namely, the bodily practices, habits, and skills through which subjects inhabit and cope with the environment, physical and social. For many pragmatists, the body is not a just an instrument that carries out orders that have their origin in the discursive realm, rather for them a subject's sensori-motor engagements with a physical and social environment already have sense before the operations of discursive reason get into the act. This type of bodily engagement is our basic way of 'being-in-the-world', and our representational dealings with things emerge from this background" 52 .

We should not however underestimate LCP. One recourse open to them, and their most likely reply, is to argue that they can incorporate all of the functions that ECP (following Dewey) attribute to the "qualitative" (including its regulative function) by

52. Levine (2012: 126). 
means of a sophisticated theoretical account of how what may seem non-linguistic can be reduced or transformed to linguistic skills or entities. For example, Brandom may give some role to emotions and feelings in discursive practices, but only after they are conceived as psychological phenomena that are relevant only insofar as they can be explained entirely in terms of inferential moves in the space of reasons; or perhaps it can be shown that what is qualitative or emotional is somehow constituted by beliefs or a discursive norm ${ }^{53}$. Another possible reply by LCP is to acknowledge functions of a qualitative dimension of life but only as psychological phenomena or forces that are causes but not reasons in inquiry. As Mark A. Wrathall and others have argued, the lingua-centric neo-pragmatists are committed to a strict dichotomy of reasons and causes. So whatever cannot be discursively redeemed goes on the brute-causation side of the dichotomy ${ }^{54}$. These possible replies would strike ECP as reductionistic (in so far as the qualitative is theoretically reduced to what is linguistic) and seems to presuppose a problematic dualism between causes and reasons. According to Steven Levine the distinctions found in Brandom "between norm and cause, mind (the space of reasons) and body (reliable response dispositions) are precisely the ones that classical pragmatists would criticize", but "Brandom, in contrast, is simply not interested in undoing the dualisms and dichotomies passed on by the classical tradition. In this respect, Brandom rejects an essential element of the pragmatic enlightenment" 55 . Reductionism and dualisms are among the problems that ECP think can be prevented by adopting experience as a methodological commitment.

Perhaps the most difficult challenge for LCP is to continue to develop their view without avoiding the implication that there is nothing that guides inquiry except language. To be sure they have a much richer and more "praxis" oriented view of discourse than the traditional analytic philosophers, but ultimately what guides discourse is just more discourse. This is what has made their version of Pragmatism liable to the charge that their resulting linguistic view of inquiry leaves no traction or friction with its context and to understand how inquiry can guide itself and avoid a linguistic idealism ${ }^{56}$. It is not obvious how even the sort of practical mastery of

53. In a recent interview Brandom was asked what was the importance of emotions in discursive practices. He replies, "I think they can come in in two ways. First of all, there is the Kantian principle that 'ought implies can' which has led people thinking about ethics and ethical normative evaluations of individual actions to be properly concerned with moral psychology, for instance, with the way in which psychological issues affect what people can do, what situations they can become sensitive to. And I think that there may well be an analogous set of considerations in the political case where we are not talking so much about the actions of individuals as we are about the way in which normative statuses and normative attitudes of people occupying different roles within an institution change. The second way in which emotional or, more broadly, psychological issues can matter in the political context of course has to do with our aim. It may well be that the aims of many of the participants in a political process concern the emotional well-being or status, the psychological status, of various people who are affected by the outcome of that political process, in which case psychology is going to matter in politics". [www.pitt.edu/ brandom/downloads/Brandom Interview Pritzlaff 2008\%5B1\%5D.pdf] 54. On how the distinction between reasons and causes (found in Quine, Davidson, Rorty, McDowell, and Brandom) and how it can be questioned see Wrathall 2004; Kukla, and Lance 2014; Sachs 2012. 55. Levine (2012: 127)

56. In "The Demand for Transcendental Friction: Avoiding Idealism", in C. I. Lewis, Sellars, and McDowell" (paper read at 2014 Eastern APA) Carl B. Sachs argues that a central theme in C. I. Lewis, 
"norms implicit in linguistic practice" found in the normative theory of Brandom can avoid the charge or danger of sliding into a form of Pragmatism that is close to a language-communal relativism.

The debate between LCP and ECP will continue. I am hopeful that the clarifications and provocations provided in this paper will contribute to having a more genuine and fruitful debate among pragmatists. LCP should show the fruits of its linguistic starting point, as I have shown the fruits of experience, so that at least the undecided can determine whether Pragmatism is better of going with "experience" or "language". For ECP we must not abandon experience but work with the insights about experience inherited from James and Dewey so that we can continue to develop our rich account of inquiry. This is how we must chart Pragmatism's course for the twentieth century.

\section{References}

Aikin S. F., (2009), "Pragmatism, Experience and the Given”, Human Affairs, 19, 19-27.

Alexander T., (2013), The Human Eros, New York: Fordham University Press.

Bernstein R., (2010), The Pragmatic Turn, Cambridge: Polity Press.

Brandom R. B., (2002), "Pragmatics and Pragmatism”, in Hilary Putnam: Pragmatism and Realism, ed. by J. Conant, and U. M. Zeglen, New York, Routledge.

— (2011), Perspectives on Pragmatism, Boston: Harvard University Press.

Burke T., (1994), Dewey's New Logic: A Reply to Russell, Chicago: University of Chicago Press.

Demasio A., (2003), Of Appetites and Emotions. Looking for Spinoza: Joy, Sorrow, and the Feeling Brain, New York: Mariner Books.

Dewey J., (1910), "How We Think”, in The Middle Works of John Dewey, 18991924, vol. 6, ed. by J.A. Boydston, Carbondale: Southern Illinois University Press, 1977.

W. Sellars, and John McDowell is the need to satisfy what he calls "the demand for transcendental friction": that it must be possible, by reflecting on our basic cognitive capacities as manifest in firstperson experience, to guarantee that we are in contact with a reality that we discover and do not create. Beck shows how Lewis, Sellars, and McDowell each attempt to satisfy the Demand and argue that none of them do so adequately. 
Dewey J., (1967), The Early Works of John Dewey, 1882-1898, ed. by J. A. Boydston, Carbondale: Southern Illinois University Press.

- (1977), The Middle Works of John Dewey, 1899-1924, ed. by J.A. Boydston, Carbondale: Southern Illinois University Press.

- (1984), The Later Works of John Dewey, 1925-1953, ed. by J.A. Boydston, Carbondale: Southern Illinois University Press.

- (2012), Unmodern Philosophy and Modern Philosophy, ed by P. Deen, Carbondale: Southern Illinois University.

Green J., and Haidt J., (2002), “How (and Where) Does Moral Judgment Work?", Trends in Cognitive Science, 6, 12, 517-523.

Güzeldere G., (1998), “The Many Faces of Consciousness: A Field Guide”, in The Nature of Consciousness: Philosophical Debates, ed. by N. Block, O. Flanagan, and G. Güzeldere, Boston: MIT Press, 1998.

Haidt J., (2001), “The Emotional Dog and Its Rational Tail: A Social Intuitionist Approach to Moral Judgment”, Psychological Review, 108, 814-834.

- (2006), The Happiness Hypothesis: Finding Modern Truth in Ancient Wisdom, New York: Basic Books.

— (2007), “The New Synthesis in Moral Psychology”, Science, 998-1002.

- (2012), The Righteous Mind: Why Good People are Divided by Politics and Religion, New York: Pantheon Books.

Haidt J., and Joseph C., (2004), “Intuitive Ethics: How Innately Prepared Intuitions Generate Culturally Variable Virtues", Daedalus, Fall, 55-66.

Hare R. H., (1981), Moral Thinking: Its Levels, Method and Point, Oxford: Clarendon Press.

Hauser M., (2006), Moral Minds: How Nature Designed Our Universal Sense of Right and Wrong, New York: Harper Collins.

Hauser M., Young L., and Cushman F., (2008), "Reviving Rawls's Linguistic Analogy: Operative Principles and the Causal Structure of Moral Actions", in Moral Psychology, Vol. 2: The Cognitive Science of Morality: Intuition and Diversity, ed. by W. Sinnott-Armstrong,Cambridge, MA: MIT Press. 
Hildebrand D., and Pappas G., (2010), "Review of Pragmatism as Transition", Notre Dame Philosophical Reviews, 2010.08.29, [www.ndpr.nd.edu/news/24466pragmatism-as-transition-historicity-and-hope-in-james-dewey-and-rorty/]

Johnson M., (2006), "Mind Incarnate: From Dewey to Demasio", Daedalus, 135, 3, 46-54.

- (2010), “Cognitive Science and Dewey's Theory of Mind, Thought, and Language”, in The Cambridge Companion to Dewey, ed. by M. Cochran, Cambridge: Cambridge University Press.

— (2014), Morality for Humans, Chicago: University of Chicago Press.

Koopman C., (2007), "Language is a Form of Experience: Reconciling Classical Pragmatism and Neopragmatism", Transactions of the Charles S. Peirce Society, 43, 4, 696-697.

Kukla R., and Lance M., (2014), "Intersubjectivity and Receptive Experience", Southern Journal of Philosophy Volume, 52.

Levine S., (2012), "Brandom's Pragmatism", Transactions of the Charles S. Peirce Society, 48, 2, 125-140.

Pappas G., (2008), John Dewey's Ethics: Democracy as Experience, Bloomington: Indiana University Press.

Ralston S. J., (2013), “Taking Experiential Givenism Seriously”, Sage Open, 3, JulySeptember, 1-9.

Sachs C. B., (2013), "Resisting the Disenchantment of Nature: McDowell and the Question of Animal Minds", Inquiry: An Interdisciplinary Journal of Philosophy, 55, 2, 131-147.

- (2014), "The Demand for Transcendental Friction: Avoiding Idealism in C. I. Lewis, Sellars, and McDowell”, paper read at 2014 Eastern APA.

Wrathall M.A., (2004), "Motives, Reasons, and Causes", in The Cambridge Companion to Merleau-Ponty, T. Carman and M. Hansen, Cambridge, Cambridge University Press. 